This item was submitted to Loughborough's Research Repository by the author.

Items in Figshare are protected by copyright, with all rights reserved, unless otherwise indicated.

\title{
When hearing loss masquerades as cognitive decline
}

PLEASE CITE THE PUBLISHED VERSION

https://doi.org/10.1136/jnnp-2020-324707

PUBLISHER

BMJ Publishing Group

VERSION

AM (Accepted Manuscript)

PUBLISHER STATEMENT

This article has been accepted for publication in Journal of Neurology, Neurosurgery and Psychiatry, 2020 following peer review, and the Version of Record can be accessed online at https://doi.org/10.1136/jnnp-2020324707.

\section{LICENCE}

CC BY-NC 4.0

\section{REPOSITORY RECORD}

Fullgrabe, Christian. 2020. "When Hearing Loss Masquerades as Cognitive Decline". Loughborough University. https://hdl.handle.net/2134/12967757.v1. 
When hearing loss masquerades as cognitive decline

Audibility and processing effort can bias cognitive-test performance

\author{
Christian Füllgrabe \\ School of Sport, Exercise and Health Sciences \\ Loughborough University \\ Ashby Road \\ Loughborough LE11 3TU \\ United Kingdom \\ c.fullgrabe@lboro.ac.uk
}

Word count: 494 


\section{When hearing loss masquerades as cognitive decline}

\section{Füllgrabe}

\section{Audibility and processing effort can bias cognitive-test performance}

In recent years, dementia research has increasingly focused on age-related hearing loss and its association with accelerated cognitive decline and contribution to dementia risk. ${ }^{1}$

In this issue, Parker et $a l^{2}$ (pp 172-6) investigated whether pure-tone audiometric thresholds (an indicator of peripheral hearing status) predict biomarkers of dementiaassociated cerebral pathologies and cognitive performance in the preclinical older population. Hearing thresholds were indeed negatively associated with scores on the Mini-Mental-State Examination (MMSE), a widely used screen for cognitive impairment. However, the authors noticed that this relationship was no longer significant when the auditory-based repetition item of the MMSE ("No ifs, ands, or buts.") was excluded from the analysis.

From an audiological point of view, this finding is not surprising. Sibilant consonants, such as the plural marker "s" in the English version of the repetition item, are characterized by high-frequency acoustic energy. Age-related hearing loss, which affects a large proportion of the general older population, manifests itself mainly in that frequency range.

Consequently, those participants in the study of Parker et al ${ }^{2}$ with larger hearing losses struggled to hear the word-final sounds, and incompletely and thus (according to the MMSE scoring rules) incorrectly repeated the item.

Clearly, interpreting this failure as a sign of cognitive pathology would be absurd, but few are the neuropsychological or cognitive tests that caution against a possible audibility bias in the older test population, and that include procedures to ensure that test stimuli are correctly perceived.

To complicate matters further, even in the case of good audibility, age-related suprathreshold auditory processing deficits that are not reflected in the audiogram ${ }^{3}$ distort auditory information. As a result, cognitive effort is required for the processing of the test stimuli, thereby reducing the remaining cognitive resources available for the execution of the cognitive task itself $f^{4}$ (e.g. memorizing a list of items, as used in many dementia screens). This effortfulness hypothesis of cognitive performance is consistent with results from a recent study simulating age-related hearing loss in young normal-hearing participants with no cognitive impairment. Despite test stimuli being fully intelligible, auditory short-term and working memory were significantly affected compared to when no hearing-loss simulation was used. ${ }^{5}$ 
In summary, Parker et al's ${ }^{2}$ serendipitous observation is a timely illustrative reminder that age-related auditory deficits negatively impact test performance, potentially resulting in the mis- or overdiagnosis of cognitive decline. Crucially, the reduction in audibility, which can be compensated for by increasing the presentation level of the test stimuli (e.g. via the use of hearing aids), represents only one aspect of the challenges older people face when taking cognitive tests. In addition, increased processing effort associated with hearing loss and advanced age hampers cognitive-test performance. ${ }^{4,5}$ It is currently unclear how this could be mitigated.

To conclude, given the ubiquitous nature of hearing loss in the elderly who also constitute the target population for dementia diagnosis and research, clinicians and researchers need to carefully choose their cognitive tests to minimize the impact of hearing impairment on the assessment of cognitive functioning.

\section{REFERENCES}

1. Livingston G, Sommerlad A, Orgeta V, et al. Dementia prevention, intervention, and care. The Lancet 2017;390(10113):2673-734. doi: 10.1016/S0140-6736(17)31363-6

2. Parker T, Cash DM, Lane C, et al. Pure tone audiometry and cerebral pathology in healthy older adults. J Neurol Neurosurg Psychiatry 2020;91(2):172-76. doi: 10.1136/jnnp2019-321897

3. Füllgrabe C, Moore BCJ, Stone MA. Age-group differences in speech identification despite matched audiometrically normal hearing: contributions from auditory temporal processing and cognition. Front Aging Neurosci 2015;6:347. doi: 10.3389/fnagi.2014.00347

4. Wingfield A, Tun PA, McCoy SL. Hearing loss in older adulthood - What it is and how it interacts with cognitive performance. Curr Dir Psychol Sci 2005;14(3):144-48. doi: 10.1111/j.0963-7214.2005.00356.x

5. Füllgrabe C. On the possible overestimation of cognitive decline: The impact of agerelated hearing loss on cognitive-test performance. Front Neurosci 2020;14:454. doi: $10.3389 /$ fnins. 2020.00454

"This article has been accepted for publication in the Journal of Neurology, Neurosurgery, and Psychiatry (2020) following peer review, and the Version of Record can be accessed online at 10.1136/jnnp-2020-324707." 